\title{
Article
}

\section{Analysis of physical-activity profiles when running with the ball in a professional soccer team}

Carling, C.

Available at http://clok.uclan.ac.uk/12267/

Carling, C. ORCID: 0000-0002-7456-3493 (2010) Analysis of physical-activity profiles when running with the ball in a professional soccer team. Journal of Sports Sciences, 28 (3). pp. 319-326. ISSN 0264-0414

It is advisable to refer to the publisher's version if you intend to cite from the work. http://dx.doi.org/10.1080/02640410903473851

For more information about UCLan's research in this area go to http://www.uclan.ac.uk/researchgroups/ and search for < name of research Group>.

For information about Research generally at UCLan please go to http://www.uclan.ac.uk/research/

All outputs in CLoK are protected by Intellectual Property Rights law, including Copyright law. Copyright, IPR and Moral Rights for the works on this site are retained by the individual authors and/or other copyright owners. Terms and conditions for use of this material are defined in the policies page.

\section{CLoK}

Central Lancashire online Knowledge www.clok.uclan.ac.uk 
This is a pre-proof corrected manuscript, as accepted for publication, of an article published by Taylor \& Francis in Journal of Sports Sciences on $12^{\text {th }}$ January 2010. The final publication is available at:

http://www.tandfonline.com/doi/abs/10.1080/02640410903473851\#.VbPdMvlVhBc

PLEASE REFER TO THE PUBLISHED VERSION FOR CITING PURPOSES

\section{Analysis of physical-activity profiles when running with the ball in a professional soccer team}

Authors: ${ }^{1}$ Christopher Carling

Institutions:

${ }^{1}$ Ecole des Métiers du Sport Professionnel, LOSC Lille Métropole Football Club, Domain de Luchin, Camphin-en-Pévèle, 59780, France.

Correspondance: Ecole des Métiers du Sport Professionnel, LOSC Lille Métropole Football Club, Domain de Luchin, Camphin-en-Pévèle, 59780, France.

Phone: 00.33.1.48910793

Fax: 00.33.1.48910793

Email: chris.carling@free.fr

Running head: Physical performance in elite soccer 


\begin{abstract}
This study characterised physical demands when running with the ball in a professional soccer team and (1) determined activity profiles during match play; (2) examined effects of fatigue and (3) investigated differences according to playing position. Thirty French League 1 matches from two competitive seasons (2007-2008, 2008-2009) were analysed using multi-camera computerised tracking. Players $(n=27)$ ran a mean total distance of $191.0 \pm 38.0 \mathrm{~m}$ with the ball of which $34.3 \%$ was covered at speeds $>19.1 \mathrm{~km} / \mathrm{h}, 25.6 \%$ between $14.1-19.0 \mathrm{~km} / \mathrm{h}, 12.5 \%$ between $11.1-14.0$ $\mathrm{km} / \mathrm{h}$ and $27.6 \%$ at $<11.0 \mathrm{~km} / \mathrm{h}$. Mean distance covered per possession was $4.2 \pm 0.7$ $\mathrm{m}$, speed at ball reception was $10.3 \pm 0.9 \mathrm{~km} / \mathrm{h}$ while mean and peak speeds during runs were $12.9 \pm 1.0 \mathrm{~km} / \mathrm{h}$ and $24.9 \pm 2.4 \mathrm{~km} / \mathrm{h}$. Mean time in possession, duration and touches per possession were 53.4 $\pm 8.1 \mathrm{~s}, 1.1 \pm 0.1 \mathrm{~s}$ and $2.0 \pm 0.2$. There were differences across playing positions for all variables $(P$ at least 0.017 and effect size at least 0.5 ). Total distance run did not differ between halves but varied over the course of matches $(\mathrm{p}<0.001)$ decreasing just before half-time. These findings provide valuable information about the physical and technical requirements of running with the ball that could be useful in the prescription of general and individualised training programmes.
\end{abstract}

Key terms: fatigue, performance, football, locomotor activity, motion-analysis 


\section{Introduction}

Recently, analyses of professional soccer have identified activity profiles and physical requirements of contemporary match play (Stølen, Chamari, Castagna, \& Wisløff, 2005; Carling, Bloomfield, Nelsen, \& Reilly, 2008). Extensive research on the physical efforts of professional players across Europe and South America has shown that there are marked differences in the distances covered in various running activities according to playing position (Barros et al., 2007; Di Salvo et al., 2007, Di Salvo, Gregson, Atkinson, Tordoff, \& Drust 2009; Mohr, Krustrup, \& Bangsbo, 2003; Rienzi, Drust, Reilly, Carter, \& Martin, 2000). Understanding the physical efforts at different speeds imposed during competition on players according to their positional role is necessary to develop and optimise physical preparation regimes to respond to the specific demands of elite-standard match-play.

In professional soccer, only $1.2-2.4 \%$ of the total distance covered by players is in possession of the ball with distances dependant on playing position (Di Salvo et al., 2007). Nevertheless, it has been shown that running with the ball increases physiological stress compared with normal running (Reilly \& Ball, 1984; Hoff, Wisløff, Engen, Kemi, \& Helgerud, 2002). The additional energy expenditure required for this match activity should therefore be taken into account when evaluating physical performance. Furthermore, research in professional soccer has identified substantial differences in the overall distance covered with the ball (Rampinini, Impellizzeri, Castagna, Coutts, \& Wisløff, 2009) and in distances covered with the ball at high speeds across playing positions (Rampinini, Coutts, Castagna, Sassi, \& Impellizzeri, 2007). In addition, players in highly ranked professional Italian soccer teams ran greater distances with the ball than counterparts from lower ranked teams (Rampinini, Impellizzeri, Castagna, Coutts, \& Wisløff 
2009). Finally, the physical efforts of professional players when in possession of the ball have substantially increased in the contemporary game compared with previous decades (Di Salvo et al., 2007).

Motion-analyses of elite-standard soccer have identified a reduction in highspeed efforts between playing halves and towards the end of matches (Mohr, Krustrup \& Bangsbo, 2005; Carling, et al, 2008; Reilly, Drust \& Clarke, 2008). Match-related fatigue has also been shown to affect physical efforts with the ball (Rampinini et al., 2009) as elite Italian soccer players ran substantially less distance in possession during the second half of competition. However, there is contrasting evidence as no decline in performance between halves was reported in top Spanish and English players (Di Salvo et al., 2007) suggesting an additional need for research. Moreover, the authors did not determine if variations in performance between halves were specific to playing positions in a team. Similarly, no study has examined whether or not physical performance with the ball varies over different match intervals and if variations depend on playing position. This discrepancy is important as research in professional English players has shown that off-the-ball efforts during attacking play decrease as matches progress (Bradley et al., 2009). For example, the distance covered by the players at high-speeds during attacking play in the last 15 -min period of the game was $23.0 \%$ less than in the first 15 -min period.

While research on variations in activity with the ball has important practical implications, there is no information on the range of speeds at which outfield players receive possession and subsequently run with the ball, including the length and duration of running actions and number of touches taken, and if performance in these areas depends on playing position. Information about these areas in the evaluation of the physical demands in possession in elite soccer would inform the design and 
prescription of fitness and technical-training drills. Consequently, the aims of this study on the physical demands with the ball were to (1) determine physical activity profiles in a professional soccer team when running with the ball; (2) examine effects of fatigue over matches; (3) investigate technical aspects of individual ball possession and (4) identify whether or not there are differences in performance across playing positions.

\section{Methods}

\section{Participants and match sample}

With ethics approval from the internal review board of the sampled football club, physical demands in ball possession were analysed for 27 outfield soccer players from a professional soccer team that competed in the French League 1 division (highest standard in French soccer). Participants were fully informed of all experimental procedures before giving their informed consent to participate in the study. To ensure team and player confidentiality, all performance data were anonymised before analysis.

Players were categorised into one of five individual playing positions. These positions included full-backs, central-defenders, wide- and central-midfielders and centre-forwards. This categorisation resulted in the inclusion of 5 full-backs and central-defenders and 6 wide-midfielders, central-midfielders and centre-forwards respectively. The sample included only players that played in their customary position.

A total of 30 French League games over two seasons (from mid- to endseason 2007/2008 and from start- to mid-season 2008/2009) were included for 
analyses. The sample included 19 home and 11 away matches in which players completed the entire match. Altogether, 228 observations of match performance were obtained with a median of 6.5 games per player (range $=1-24)$. The total number of observations of match performance for each player is presented in Table 1.

\section{Data collection procedures and measures of competitive performance}

A computerised player tracking system (AMISCO Pro ${ }^{\circledR}$, Sport-Universal Process,

Nice, France) was used to characterise activity profiles in the team. This multiplecamera system tracked the movements of every player over the course of matches. It provided information on running speeds, distances covered, time spent in different categories of movement and the frequency of occurrence for each activity. Player movements were tracked at a sampling rate of $25.0 \mathrm{~Hz}$ providing approximately 2.5 million data points per match (Carling, Williams \& Reilly, 2005). A trained operator simultaneously coded each technical action involving the ball. The workings of the AMISCO Pro ${ }^{\circledR}$ system have been described in more detail elsewhere (Di Salvo et al, 2007; Carling, Williams \& Reilly, 2005; Carling et al., 2008).

Physical performance with the ball was determined automatically by computerised analysis of player movements and actions using match-analysis software (AMISCO Viewer ${ }^{\circledR}$, Sport-Universal Process, Nice, France).

The measures of performance with the ball selected for the analyses were classified into four categories: 1) Match distances covered in individual possession of the ball that included total distance covered and distance covered in four categories of movement speed based on a slightly modified version of the thresholds previously employed in other studies of performance in competitive elite soccer (Di Salvo et al., 
2007, Carling and Bloomfield, in press): 0.0-11.0 km/h (light speed); 11.1-14.0 km/h (low speed); 14.1-19.0 km/h (moderate speed); >19.1 km/h (high speed and sprinting combined). 2) To investigate the effects of fatigue on this component of physical performance, measures of distance were compared between the two match halves and across six intervals in games (0'00-14'59 mins, 15'00-29'59 mins, 30'00-44'59 mins, 45'00-59'59 mins, 60’00-74'59 mins and 75'00-90'00 mins). 3) Running speeds in possession were analysed and included peak speed in possession, mean speed of all actions and mean speed of the player at ball reception. Peak speed was considered as the maximal running speed in possession attained by each player during a match. 4) Analysis of technical skills included the mean number of ball possessions and time spent in ball possession, mean number of touches and mean time per possession and mean distance from the nearest opponent when the player received the ball.

\section{Statistical Analyses}

All statistical analyses were conducted using SPSS for Windows Version 14.0 (SPSS Inc., Chicago, IL, USA). All results are reported as means and standard deviations $($ mean $\pm \mathrm{SD})$ calculated by conventional procedures unless otherwise stated. Before using parametric statistical test procedures, the normality of the data was verified. A one-way analysis of variance (ANOVA) was used to test for differences in means in performance measures between playing positions. A two-way ANOVA was used to explore differences in means for distance covered in each category of running speed between playing positions. To investigate fatigue across match halves, a three-way ANOVA was performed to examine the interaction between playing position and total distance covered and distance covered at four running speeds across match 
halves. To isolate any differences in total distance covered according to playing position between the three intervals across each half, a two-way ANOVA was used. Follow-up univariate analyses using Bonferroni-corrected pair wise comparisons were used where appropriate.

To control the Type-I error rate, a pseudo-Bonferroni adjustment was applied according to previously outlined procedures for objective measures of physical performance in elite soccer (Rampinini et al., 2007, 2009). In the present study, these objective measures of ball possession included distances run, running speeds and technical parameters. Thus, an operational alpha level of $0.017(P<0.05 / 3)$ was used. Effect sizes for these differences were also determined. Effect size values of 0.2, 0.5 and above 0.8 were considered to represent small, medium and large differences, respectively (Cohen, 1998).

\section{Results}

\section{Match distances covered with the ball}

During matches, a mean distance of $191.0 \pm 80.3 \mathrm{~m}$ in possession of the ball was covered by the players (Table 1). This figure accounted for $1.7 \pm 0.7 \%$ of the total match distance covered. Altogether, $34.3 \%$ of distance in possession was covered at speeds $>19.1 \mathrm{~km} / \mathrm{h}, 25.6 \%$ between $14.1-19.0 \mathrm{~km} / \mathrm{h}, 12.5 \%$ between $11.1-14.0 \mathrm{~km} / \mathrm{h}$ and $27.6 \%$ at $<11.0 \mathrm{~km} / \mathrm{h}$. A difference was observed in the total distance run across the four categories of movement speed $(P<0.001)$. Post hoc analyses revealed greater distances covered at speeds between $0.0-11.0 \mathrm{~km} / \mathrm{h}, 14.1-19.0 \mathrm{~km} / \mathrm{h}$ and $>19.1 \mathrm{~km} / \mathrm{h}$ compared to between 11.1-14.0 km/h (all $\mathrm{p}<0.001$ ). These differences were associated with large effect sizes $(\geq 0.8)$. 
The results of the two-way ANOVA revealed a significant main effect for total distance run with the ball across playing positions $\left(\mathrm{F}_{4,12}=17.47 ; P<0.001\right)$. The wide-midfielders covered the greatest distances (see Table 1). Moderate to large effect sizes were observed for the differences in these players compared to all other positions (0.6-1.2). In addition, the percentage of the overall distance covered over entire games when the player was in possession of the ball varied between positions $(P<0.001)$ and was highest in wide-midfielders while lowest (identical) values were observed in fullbacks, in central-defenders and centre-forwards.

There was also a significant interaction between playing position and distance covered in each category of running speed $\left(\mathrm{F}_{3,12}=10.17 ; P<0.001\right)$. These differences were accompanied by high effect sizes (0.6- $\geq 1.0)$. Post hoc analyses showed that central-midfielders covered the most distance at speeds between 0-11.0 $\mathrm{km} / \mathrm{h}$ and $11.1-14.0 \mathrm{~km} / \mathrm{h}$ whereas this was the case for wide-midfielders at speeds between $14.1-19.0 \mathrm{~km} / \mathrm{h}$ and $>19.1 \mathrm{~km} / \mathrm{h}$.

The mean distance covered per ball possession by players was $4.0 \pm 1.9 \mathrm{~m}$ (Table 1). Analysis of the mean distance completed per ball possession demonstrated a difference across playing positions $(P<0.001$, effect sizes $0.5-1.0)$ with highest and lowest values observed in wide-midfielders and fullbacks respectively.

Insert Table 1 about here.

Effect of fatigue on ball possession

The total distance covered in each match half and across six intervals in all players is reported in Figure 1. Across all players, the three-way ANOVA revealed no significant main effect in the total distance covered between the two game halves 
$\left(\mathrm{F}_{1,4}=0.07 ; P=0.795\right)$ or in the total distance covered at each running speed between halves $\left(\mathrm{F}_{3,12}=2.22 ; \quad P=0.085\right)$. While an interaction approaching significance was yielded between individual playing position and total distance covered in each match half $\left(\mathrm{F}_{1,4}=2.38 ; P=0.050\right)$, there was no interaction between playing position and distance covered in the four categories of running speed across each half $\left(\mathrm{F}_{4,12}=0.67 ; P=0.785\right)$.

Across all players, a two-way ANOVA yielded a significant main effect for distance covered across six equal time intervals over the course of games $\left(\mathrm{F}_{4}\right.$, ${ }_{20}=15.88 ; P<0.017$ ) (Figure 1). Players ran greater distances in the first interval of the first and second halves (Effect Sizes of 0.6 and 0.5 respectively) compared to the final interval in the first half. However, there was no significant interaction between playing position and distance run across match intervals $\left(\mathrm{F}_{5,20}=0.87 ; P=0.757\right)$.

Insert Figure 1 about here.

\section{Running speeds}

In Table 2, a mean running speed per ball possession of $12.9 \pm 1.8 \mathrm{~km} / \mathrm{h}$ can be observed across all players with a difference across positions $(P<0.001$, effect sizes 0.5-1.3). Mean running speed in possession was highest in centre-forwards and lowest in fullbacks.

Across all positions, the mean speed on reception of the ball was $10.3 \pm 1.8$ $\mathrm{km} / \mathrm{h}$. A difference was observed across playing positions $(P<0.001)$ with the highest speeds reported in wide-midfielders and centre-forwards and the lowest values in fullbacks. Moderate to large effect sizes were observed for the differences across positions $(0.5-2.4)$. 
In all players, the peak speed in possession was measured as $24.7 \pm 6.1 \mathrm{~km} / \mathrm{h}$ with a difference observed between playing positions $(P<0.001)$. Highest and lowest values were reported in wide-midfielders and central-defenders respectively. Effect sizes ranged from $0.5-0.8$ for these differences.

Insert Table 2 about here.

\section{Technical performance}

Players had a mean of $46.7 \pm 9.1$ individual possessions per match with a difference observed across playing positions $(P<0.001)$ (Table 2$)$. A substantially higher number of ball possessions was completed in fullbacks, central- and widemidfielders compared to central-defenders and centre-forwards (effect Sizes $\geq 1.0$ ).

The mean number of touches per possession across all players was $2.0 \pm 0.2$ and varied between playing positions $(P<0.001)$. Effect sizes observed for these differences across positions ranged from 0.6-1.8. The mean number of touches per possession was highest in wide-midfielders and lowest in fullbacks respectively.

On average, players spent $53.4 \pm 8.1$ seconds per match in possession. A difference across playing positions was observed $(P=0.002)$ with a greater amount of time spent in possession reported in wide-midfielders compared to centreforwards $(P<0.01$, Effect Size 0.8).

A mean duration of $1.1 \pm 0.1$ seconds for possessions was observed and values varied across playing positions $(P<0.001)$. The mean duration of possessions was longest in wide-midfielders and shortest in fullbacks. Moderate to large effect sizes (0.6-1.6) were observed for these differences. 
On reception of the ball, players were at a distance of $4.0 \pm 1.2$ from an opponent. Mean distances differed across playing positions $(P<0.001)$. Fullbacks and wide-midfielders had the least and most space respectively on ball reception compared to the other positions. Effect sizes for these differences ranged from 0.72.1 respectively.

\section{Discussion}

In this study, a detailed investigation of the physical activity profiles of professional soccer players with the ball was performed. The major findings were that differences exist in the total distance covered in possession at various movement speeds and that these differences are dependent on playing position. Mean speed at which players were running when they received the ball was in the light-speed range $(\sim 10.0 \mathrm{~km} / \mathrm{h})$ although reception speed varied according to playing position. The mean distance, duration and speed of possessions, number of touches taken and distance from nearest opponent when receiving the ball also varied across playing positions. Finally, the physical efforts in ball possession did not change between match halves but varied over the course of the game, notably decreasing just before the half-time interval.

The present results $(1.7 \%)$ confirm findings from previous studies (Di Salvo et al., 2007; Rampinini et al., 2009) in that only a small percentage of the total distance run is in possession of the ball. However, the analysis of efforts when running with the ball showed that actions are most commonly undertaken at high running speeds. Therefore, the capacity to move at high speed with the ball seems to be an extremely important facet of contemporary elite soccer and players across all positions should be able to carry out such actions. This statement is supported by findings from a 
recent study in professional Italian soccer which showed that the most successful teams competing in the top League (5 highest in ranking) covered substantially greater distances at high speeds with the ball than less successful teams (5 lowest in ranking) (Rampinini et al., 2009). Furthermore, the significant change in the tempo of the game over recent years through a marked increase in the number of actions with the ball (Williams, Lee \& Reilly, 1999; Di Salvo et al, 2007) lends further weight to the present findings.

Previous research has shown that for a given speed of locomotion, the training stimulus is higher when running with the ball than normal running, suggesting benefits of soccer-specific routines wherever possible (Reilly, 2005). Indeed, highlevel U/17 (McMillan, Helgerud, Macdonald, \& Hoff, 2005) and senior professional soccer players (Hoff, Wisløff, Engen, Kemi, \& Helgerud, 2002) used a circuit to initially test and subsequently develop endurance capacity in soccer players based on dribbling actions with the ball. However, it is not clear if the circuit was designed using information on the physical demands of competition obtained from match analyses even if the test did include variations in running speeds. The present results show that the highest percentage of movements with the ball was undertaken at high movement speeds $(>19.1 \mathrm{~km} / \mathrm{h})$. This suggests that aerobic training circuits using the ball should be based on movements carried out at high speeds to resemble the actual demands of the game. Nevertheless, including a range of movement speeds similar to those determined in the present study would be relevant especially as actions undertaken at moderate speeds were also common. Furthermore, a large part of the actions with the ball were undertaken at speeds of less than $11.0 \mathrm{~km} / \mathrm{h}$ ). This result was probably due to players making an immediate choice on whether to carry the ball or to release it quickly without attempting a run or dribble. In the latter case, the 
mean speed of the action would therefore be restricted. A future study that breaks down the speeds and distances of actions in which only a dribble or run with the ball was undertaken could be useful in aiding the design of precise testing and training prescriptions for this important aspect of soccer play.

Two recent reviews on physical activity profiles in elite soccer have confirmed the need for individualised training programs as the distances covered at different speeds vary according to playing position (Stølen et al., 2005; Carling et al., 2008). In the present report, a greater total distance with the ball was covered by widemidfielders and agrees with findings from research in other professional European players (Di Salvo et al., 2007). However, unlike the present report, Di Salvo et al. (2007) did not provide any information on the different speeds at which players run with the ball. In contrast, a recent study by Rampinini et al. (2007) in elite Italian soccer reported substantial differences in high speed running with the ball across the playing positions although players were grouped into four positional groups compared with five in the present study. The substantial difference reported across these five playing positions in distance covered with the ball at several running speeds and especially at high speeds (notably in wide-midfielders) is therefore noteworthy. In addition, the current data are the first to show that the mean distance of running actions with the ball is also dependent on playing position. These findings imply that fitness-training routines both with and without the ball should be based on the specific requirements of each individual playing position.

No differences between the two game halves were observed across all players in the distance covered in any of the four separate categories of running speed. This result suggests that this element of performance is not affected by game-related fatigue. During the second half the total distance covered was shown to increase 
although the magnitude of the change was small (effect size 0.1). Furthermore, in some playing positions, substantially further distances were covered at certain running speeds during the second-half (e.g. a $35.3 \%$ increase in efforts at speeds $>19.1 \mathrm{~km} / \mathrm{h}$ in central-midfield players). Previous studies on the differences in the physical efforts with the ball between game halves have provided conflicting evidence. Work by Rampinini et al. (2009) reported a greater total distance covered in the first-half $(\sim 5.0 \%)$ whereas Di Salvo et al. (2007) reported a $4.6 \%$ increase in the second half, a result which is higher than the second-half increase $(2.0 \%)$ observed in this study. It is difficult to suggest valid reasons for an increase in second-half performance. One reason may be that players consider movements with the ball to involve risk and are therefore less willing to attempt such actions during the first half, especially as the match result is generally not yet decided. A study linking physical performance in possession of the ball with score-line is warranted.

A significant difference in overall distance covered between different time intervals across the course of games was observed with players running considerably less distances in the final interval in the first half. This result may again be due to the reasons mentioned above in that players may be less willing to run with the ball before half-time. A notable finding was the lack of a drop in overall physical performance observed during the final third of games. The distance run in this period was comparable to that of the other match intervals, a result reflected by the low effect sizes associated with the differences $(<0.3)$. This result suggests that this aspect of physical performance was not affected by game related fatigue, irrespective of playing position, as no decrease in performance at the end of games were observed across any of the positions. In contrast, other studies have demonstrated that distances covered at high running speeds (Mohr, Krustrup, \& Bangsbo, 2003; 
Bradley et al., 2009) by elite-standard players decrease substantially in the final third of games. An exploration of variations in high speed efforts with the ball across game intervals and their comparison between playing positions is warranted.

The novel approach to the evaluation of physical activity in ball possession using information on peak and mean running speed and speed at reception has led to several noteworthy findings and may provide valuable information for the design of realistic training drills notably from a technical point of view. For example, the mean speed on reception of the ball was computed as $10.3 \mathrm{~km} / \mathrm{h}$ suggesting that realistic passing drills aimed at improving ball control should ensure that the player receiving possession is moving and not static. In addition, the mean and peak speed of actions implies that drills aimed at improving dribbling technique or general running with the ball should be carried out at minimum speeds of around $13.0 \mathrm{~km} / \mathrm{h}$ and include actions at high speeds $(\sim 25.0 \mathrm{~km} / \mathrm{h})$ regardless of playing position. The result showing a significantly higher mean $(14.0 \mathrm{~km} / \mathrm{h})$ speed and peak speed $(28.3 \mathrm{~km} / \mathrm{h})$ in possession in wide-midfielders would however, lead us to recommend that these particular players follow individualised conditioning programs based on the above information to improve tolerance to the specific demands of this position.

The technical measures of physical activity with the ball demonstrate that differences exist across playing positions in the total time spent in possession and the mean duration and number of touches in each possession. This finding may again encourage practitioners to create position-specific training drills. However, the results across all players generally show the extremely short nature of actions in this component of physical activity ( 1.0 second and 2.0 ball touches per action). These results may be related to a lack of time on the ball as the player receiving possession was, on average, at a distance of less than 4.0 metres from an opposition player. 
Indeed, fullbacks reported the lowest number of touches per possession and were frequently closer to an opposition player when receiving the ball than team mates in other positions. These findings indicate the importance of creating space in which to make the most of the limited in time possession as well as good technique in controlling the ball.

The major limitations of this study were the relatively low number of games examined and that players came from only one club. Therefore, the patterns observed might be a reflection of only this particular team. In addition, the techniques used to collect motion analysis data must meet the requirements for criteria for quality control (Carling et al., 2008). These criteria include reliability, objectivity and validity. There is a need for a detailed analysis of the errors associated with the analytical procedures in motion analysis (Drust, Atkinson, \& Reilly, 2007). Although the present system has been widely adopted across professional European soccer and used in several recent scientific publications (Carling and Bloomfield, in press; Carling, Espié, Le Gall, Bloomfield, \& Jullien, in press; Di Salvo et al, 2007; Zubillaga, Gorospe, Hernadez-Mendo, \& Blanco-Villanesor, 2008), its true scientific legitimacy has yet to be established.

In summary, the present study provided a comprehensive evaluation of physical activity profiles in an elite soccer team when players ran with the ball. In addition to identifying the general demands for elite soccer in terms of the distance covered at varying speeds and the speed of actions with the ball, the results have demonstrated a large variation in efforts across playing positions. These findings have broadened the understanding of this key component of soccer play and could aid in developing subsequent training drills to optimise physical and technical performance as well as designing soccer-specific test protocols. However, further research is warranted to 
address other factors that may influence performance with the ball. Work could be extended to examine the effects of score line, standard of opposition, match location, match type (domestic cup competitions versus league games) or the influence of specific team formations (systems of play). 


\section{References}

Barros, R.M.L., Misuta, M.S., Menezes, R.P., Figueroa, P.J., Moura, F.A., Cunha, S.A., et al. (2007). Analysis of the distances covered by first division Brazilian soccer players obtained with an automatic tracking method. Journal of Sports Science and Medicine. 6, 233-242.

Bradley, P.S., Sheldon, W., Wooster, B., Olsen, P., Boanas P., \& Krustrup, P. (2009). High-intensity running in FA Premier League soccer matches. Journal of Sports Sciences, 27, 159-168.

Carling, C., Williams, A.M., \& Reilly T. (2005). The Handbook of Soccer Match Analysis. Abingdon, UK: Routledge.

Carling, C., Bloomfield, J., Nelsen, L., \& Reilly, T. (2008). The role of motion analysis in elite soccer: Contemporary performance measurement techniques and work-rate data. Sports Medicine, 38, 839-862.

Carling, C., \& Bloomfield, J. The effect of an early dismissal on player work-rate in a professional soccer match. Journal of Science and Medicine in Sport, doi:10.1016/j.jsams.2008.09.004.

Carling, C., Espié, V., Le Gall, F., Bloomfield, J., \& Jullien, H. (2009) Work-rate of substitutes in elite soccer: a preliminary study. Journal of Science and Medicine in Sport, doi:10.1016/j.jsams.2009.02.012.

Cohen, J. (1988). Statistical power analysis for the behavioural sciences. 2nd ed. Hillsdale, NJ: Lawrence Erlbaum.

Di Salvo, V., Baron, R., Tschan, H., Calderon Montero, F.J., Bachl, N., \& Pigozzi, F. (2007). Performance characteristics according to playing position in elite soccer. International Journal of Sports Medicine, 28, 222-227. 
Di Salvo, V., Gregson, W., Atkinson, G., Tordoff, P., \& Drust, B. (2009). Analysis of high intensity activity in Premier League soccer. International Journal of Sports Medicine, 30: 205-212.

Drust, B., Atkinson, G., \& Reilly, T. (2007). Future Perspectives in the Evaluation of the Physiological Demands of Soccer. Sports Medicine, 37, 783-780.

Hoff, J., Wisløff, U., Engen, L.C., Kemi, O.J. \& Helgerud, J. (2002). Soccer specific aerobic endurance training. British Journal of Sports Medicine, 36, 218-221.

McMillan, K., Helgerud, J., Macdonald, R., \& Hoff J. (2005). Physiological adaptations to soccer specific endurance training in professional youth soccer players British Journal of Sports Medicine, 39, 273-277.

Mohr, M., Krustrup, P., \& Bangsbo, J. (2003). Match performance of high-standard soccer players with special reference to development of fatigue. Journal of Sports Sciences, 21, 519-528.

Mohr, M., Krustrup, P., \& Bangsbo J. (2005). Fatigue in soccer: A brief review. Journal of Sports Sciences, 23, 593-599.

Rampinini, E., Coutts, A.J., Castagna, C., Sassi, R., \& Impellizzeri, F.M. (2007). Variation in top-level soccer match performance. International Journal of Sports Medicine, 28, 1018-1024.

Rampinini, E., Impellizzeri, F.M., Castagna, C., Coutts, A.J, \& Wisløff, U. (2009). Technical performance during soccer matches of the Italian Serie A league: Effect of fatigue and competitive level. Journal of Science and Medicine in Sport, 12, 227233.

Reilly T. (2005). An ergonomics model of the soccer training process. Journal of Sports Sciences, 23, 561-572. 
Reilly, T., Drust, B., \& Clarke, N. (2008). Muscle Fatigue during Football MatchPlay. Sports Medicine, 38, 357-367.

Reilly, T. \& Ball, D. (1984). The net physiological cost of dribbling a soccer ball. Research Quarterly for Exercise and Sport, 55, 267-271.

Rienzi, E., Drust, B., Reilly, T., Carter, J.E., Martin, A. (2000). Investigation of anthropometric and work-rate profiles of elite South American international soccer players. Journal Sports Medicine Physical Fitness, 40, 162-169.

Stølen, T., Chamari, K., Castagna, C., \& Wisløff, U. (2005). Physiology of soccer: an update. Sports Medicine, 35, 501-536.

Williams, A.M., Lee, D., \& Reilly, T. (1999). A quantitative analysis of matches played in the 1991-92 and 1997-98 seasons. London: The Football Association.

Zubillaga, A., Gorospe, G., Hernadez-Mendo, A., \& Blanco-Villanesor, A. (2008). Comparative analysis of the high-intensity activity of soccer players in top-level competition. In: T. Reilly, \& Korkusuz, F, (Eds.) Science \& Football VI, (pp. 182186). Abingdon, UK: Routledge. 
Tables and Figures.

Table 1: Comparison of the characteristics of physical efforts in ball possession across playing positions (mean \pm sd).

\begin{tabular}{|c|c|c|c|c|c|c|c|c|}
\hline Match performance variables & $\begin{array}{l}\text { All players } \\
(\mathrm{n}=228)\end{array}$ & $\begin{array}{l}\text { Fullbacks (FB) } \\
\qquad(n=49)\end{array}$ & $\begin{array}{l}\text { Central-defenders (CD) } \\
\qquad(n=59)\end{array}$ & $\begin{array}{l}\text { Wide-midfielders (WM) } \\
\qquad(n=35)\end{array}$ & $\begin{array}{l}\text { Central-midfielders (CM) } \\
\qquad(n=63)\end{array}$ & $\begin{array}{c}\text { Centre-forwards }(\mathrm{CF}) \\
\qquad(n=22)\end{array}$ & $\begin{array}{l}\text { Statistical } \\
\text { Difference }\end{array}$ & $\begin{array}{c}\text { Post hoc } \\
\text { (Bonferroni) }\end{array}$ \\
\hline Distance covered $(\mathrm{m})$ between $0.0-11.0 \mathrm{~km} / \mathrm{h}$ & $52.8 \pm 25.1$ & $55.9 \pm 26.6$ & $51.1 \pm 2.6$ & $55.2 \pm 16.9$ & $60.7 \pm 28.3$ & $41.3 \pm 20.3$ & $\mathrm{p}=0.132$ & \\
\hline Distance covered (m) between 11.1-14.0 km/h & $23.9 \pm 15.2$ & $18.3 \pm 11.6$ & $25.9 \pm 17.9$ & $28.9 \pm 14.9$ & $29.1 \pm 13.8$ & $17.3 \pm 9.3$ & $\mathrm{p}=0.001$ & $\mathrm{CM}>\mathrm{CF}^{\mathrm{b}} ; \mathrm{WM}>\mathrm{CF}^{\mathrm{b}}$ \\
\hline Distance covered (m) between 14.1-19.0 km/h & $48.9 \pm 27.7$ & $40.0 \pm 20.5$ & $48.4 \pm 26.5$ & $56.9 \pm 25.3$ & $56.6 \pm 30.9$ & $42.5 \pm 16.9$ & $\mathrm{p}=0.009$ & $\mathrm{CM}>\mathrm{FB}^{\mathrm{a}} ; \mathrm{WM}>\mathrm{FB}^{\mathrm{a}}$ \\
\hline Distance covered $(\mathrm{m})>19.1 \mathrm{~km} / \mathrm{h}$ & $65.3 \pm 45.2$ & $56.4 \pm 33.9$ & $35.5 \pm 26.5$ & $111.8 \pm 60.1$ & $56.3 \pm 35.9$ & $66.1 \pm 40.0$ & $p<0.001$ & $\mathrm{CF}>\mathrm{CD}^{\mathrm{a}} ; \mathrm{CM}>\mathrm{CD}^{\mathrm{b}} ; \mathrm{FB}>\mathrm{CD}^{\mathrm{b}} ; \mathrm{WM}>\mathrm{CD}^{\mathrm{c}}, \mathrm{CF}^{\mathrm{c}}, \mathrm{CM}^{\mathrm{c}}, \mathrm{FB}^{\mathrm{c}}$ \\
\hline Total distance in possession (m) & $191.0 \pm 80.3$ & $170.1 \pm 63.6$ & $162.3 \pm 70.7$ & $252.7 \pm 81.6$ & $203.2 \pm 82.9$ & $166.9 \pm 55.3$ & $\mathrm{p}<0.001$ & $\mathrm{WM}>\mathrm{FB}^{\mathrm{c}}, \mathrm{CD}^{\mathrm{c}}, \mathrm{CF}^{\mathrm{a}}$ \\
\hline$\%$ of total distance run & $1.7 \pm 0.7$ & $1.5 \pm 0.6$ & $1.5 \pm 0.6$ & $2.2 \pm 0.8$ & $1.7 \pm 0.7$ & $1.5 \pm 0.5$ & $\mathrm{p}<0.001$ & $\mathrm{WM}>\mathrm{CD}^{\mathrm{c}}, \mathrm{CM}^{\mathrm{a}}, \mathrm{FB}^{\mathrm{c}}$ \\
\hline Mean distance per action (m) & $4.0 \pm 1.9$ & $3.0 \pm 0.9$ & $4.0 \pm 1.3$ & $5.0 \pm 1.2$ & $3.8 \pm 1.2$ & $4.2 \pm 1.9$ & $p<0.001$ & $\mathrm{CD}>\mathrm{FB}^{\mathrm{c}} ; \mathrm{CF}>\mathrm{FB}^{\mathrm{b}} ; \mathrm{CM}>\mathrm{FB}^{\mathrm{b}} ; \mathrm{WM}>\mathrm{CD}^{\mathrm{b}}, \mathrm{CM}^{\mathrm{c}}, \mathrm{FB}^{\mathrm{c}}$ \\
\hline
\end{tabular}

$\mathrm{n}=$ number of observations of match performance

$\mathrm{a}=\mathrm{p}<0.017$

$\mathrm{b}=\mathrm{p}<0.01$

$\mathrm{c}=\mathrm{p}<0.001$ 
Table 2: Comparison of movement speed and technical characteristics of individual ball possessions across playing positions (mean \pm sd).

\begin{tabular}{|c|c|c|c|c|c|c|c|c|}
\hline Match performance variables & $\begin{array}{l}\text { All players } \\
(\mathrm{n}=228)\end{array}$ & $\begin{array}{l}\text { Fullbacks (FB) } \\
\qquad(n=49)\end{array}$ & $\begin{array}{l}\text { Central-defenders (CD) } \\
\qquad(n=59)\end{array}$ & $\begin{array}{l}\text { Wide-midfielders (WM) } \\
\qquad(n=35)\end{array}$ & $\begin{array}{l}\text { Central-midfielders }(\mathrm{CM}) \\
\qquad(n=63)\end{array}$ & $\begin{array}{l}\text { Centre-forwards (CF) } \\
\qquad(n=22)\end{array}$ & $\begin{array}{l}\text { Statistical } \\
\text { Difference }\end{array}$ & $\begin{array}{c}\text { Post hoc } \\
\text { (Bonferroni) }\end{array}$ \\
\hline Speed at reception $(\mathrm{km} / \mathrm{h})$ & $10.3 \pm 1.8$ & $8.9 \pm 0.9$ & $10.3 \pm 1.1$ & $11.1 \pm 1.0$ & $10.1 \pm 1.0$ & $11.1 \pm 1.4$ & $p<0.001$ & $\mathrm{CD}>\mathrm{FB}^{\mathrm{c}} ; \mathrm{CM}>\mathrm{FB}^{\mathrm{b}} ; \mathrm{CF}>\mathrm{FB}^{\mathrm{c}}, \mathrm{CM}^{\mathrm{c}} ; \mathrm{WM}>\mathrm{F}$ \\
\hline Speed in possession $(\mathrm{km} / \mathrm{h})$ & $12.9 \pm 1.8$ & $12.0 \pm 1.8$ & $12.1 \pm 1.6$ & $14.0 \pm 1.6$ & $12.4 \pm 1.6$ & $13.9 \pm 2.1$ & $\mathrm{p}<0.001$ & $\mathrm{CF}>\mathrm{FB}^{\mathrm{b}} ; \mathrm{WM}>\mathrm{CD}^{\mathrm{c}}, \mathrm{CM}^{\mathrm{c}}, \mathrm{FB}^{\mathrm{c}}$ \\
\hline Peak speed in possession $(\mathrm{km} / \mathrm{h})$ & $24.7 \pm 6.1$ & $23.7 \pm 5.7$ & $21.6 \pm 5.4$ & $28.2 \pm 4.1$ & $25.2 \pm 6.8$ & $25.0 \pm 5.0$ & $p<0.001$ & $\mathrm{CM}>\mathrm{CD}^{\mathrm{b}} ; \mathrm{WM}>\mathrm{CD}^{\mathrm{c}}, \mathrm{FB}^{\mathrm{a}}$ \\
\hline Time spent in possession (s) & $53.4 \pm 8.1$ & $51.4 \pm 20.0$ & $48.4 \pm 19.4$ & $64.3 \pm 18.0$ & $58.7 \pm 22.6$ & $44.1 \pm 29.9$ & $\mathrm{p}=0.002$ & $\mathrm{WM}>\mathrm{CF}^{\mathrm{b}}$ \\
\hline Time per possession (s) & $1.1 \pm 0.1$ & $0.9 \pm 0.3$ & $1.2 \pm 0.3$ & $1.3 \pm 0.2$ & $1.1 \pm 0.3$ & $1.1 \pm 0.4$ & $p<0.001$ & $\mathrm{CD}>\mathrm{FB}^{\mathrm{c}} ; \mathrm{CM}>\mathrm{FB}^{\mathrm{a}} ; \mathrm{WM}>\mathrm{FB}^{\mathrm{c}}$ \\
\hline Number of actions & $46.7 \pm 9.1$ & $56.4 \pm 11.6$ & $39.4 \pm 11.5$ & $50.1 \pm 10.5$ & $52.5 \pm 13.7$ & $35.0 \pm 10.3$ & $\mathrm{p}<0.001$ & $\mathrm{FB}>\mathrm{CD}^{\mathrm{c}}, \mathrm{CF}^{\mathrm{c}} ; \mathrm{CM}>\mathrm{CD}^{\mathrm{c}}, \mathrm{CF}^{\mathrm{c}} ; \mathrm{WM}>\mathrm{CD}^{\mathrm{c}}, \mathrm{CF}^{\mathrm{c}}$ \\
\hline Number touches per possession & $2.0 \pm 0.2$ & $1.8 \pm 0.2$ & $2.0 \pm 0.3$ & $2.2 \pm 0.2$ & $2.1 \pm 0.3$ & $2.0 \pm 0.4$ & $\mathrm{p}<0.001$ & $\mathrm{CM}>\mathrm{CD}^{\mathrm{a}}, \mathrm{FB}^{\mathrm{c}} ; \mathrm{WM}>\mathrm{CD}^{\mathrm{c}}, \mathrm{FB}^{\mathrm{c}}$ \\
\hline Distance from opponent on ball reception (m) & $4.0 \pm 1.2$ & $3.0 \pm 1.0$ & $4.0 \pm 1.3$ & $5.0 \pm 1.2$ & $3.8 \pm 1.4$ & $4.2 \pm 1.8$ & $\mathrm{p}<0.001$ & $\mathrm{CD}>\mathrm{FB}^{\mathrm{c}} ; \mathrm{CF}>\mathrm{FB}^{\mathrm{b}} ; \mathrm{CM}>\mathrm{FB}^{\mathrm{b}} ; \mathrm{WM}>\mathrm{CD}^{\mathrm{b}}, \mathrm{CM}^{\mathrm{c}}$ \\
\hline
\end{tabular}

$\mathrm{n}=$ number of observations of match performance

$\mathrm{a}=\mathrm{p}<0.017$

$\mathrm{b}=\mathrm{p}<0.01$

$\mathrm{c}=\mathrm{p}<0.001$ 
Figure 1: Comparison of the total distance covered with the ball between match halves and across six separate time intervals in all players.

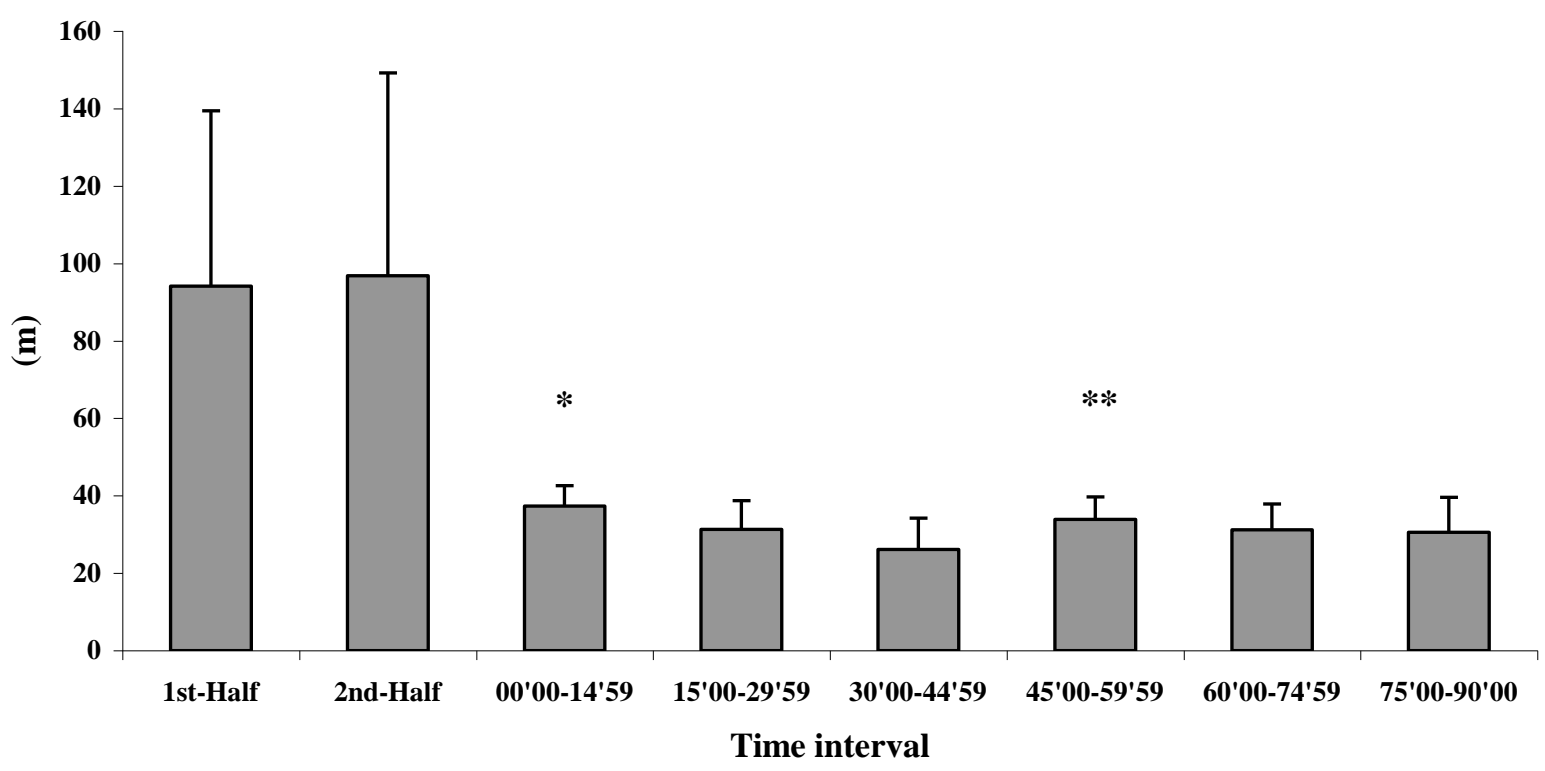

${ }^{*} \mathrm{p}<0.01$; difference in distance covered with ball compared to $30^{\prime} 00-44^{\prime} 59$ minutes interval.

** $\mathrm{p}<0.017$; difference in distance covered with ball compared to $45^{\prime} 00-59^{\prime} 59$ minutes interval. 